\title{
Ocorrência de automedicação na pandemia da COVID-19: uma revisão integrativa
}

\section{da literatura}

Occurrence of self-medication in the COVID-19 pandemic: an integrative literature review

Ocurrencia de la automedicación en la pandemia de COVID-19: una revisión integradora de la

literatura

Recebido: 29/11/2021 | Revisado: 30/11/2021 | Aceito: 04/12/2021 | Publicado: 04/12/2021

\begin{abstract}
Resumo
Objetivo: Verificar a prevalência, riscos e fatores que levam a realização da automedicação, através de uma revisão integrativa de literatura, fazendo buscas de estudos científicos nas principais bases de dados acadêmicas: Google Acadêmico, Scielo, Medline, PubMed e Redib. Métodos: A revisão de literatura foi realizada no mês de outubro de 2021, utilizando os descritores "Automedicação", "Pandemia", "COVID-19", "riscos" e "prevalência". Resultados: Após fazer uso dos critérios de inclusão e exclusão, obteve-se 12 artigos para a realização desta análise. Eles evidenciaram que a população buscou a automedicação como um meio de solução rápida e fácil para a doença, visto que ela é letal e tem uma morbidade considerável. Outra justificativa para a utilização da automedicação era a finalidade preventiva, de forma equivocada, dada a falta de comprovação cientifica sobre tratamento e/ou prevenção da COVID-19. Conclusão: Mediante os resultados apresentados, destaca-se que é de grande importância a realização de mais estudos que avaliem o uso indiscriminado de medicamentos utilizado no tratamento e/ou prevenção da doença, e se ressalta também a importância do profissional farmacêutico e da equipe multiprofissional na orientação da promoção do uso racional de medicamentos durante a pandemia da COVID-19.
\end{abstract}

Palavras-chave: COVID-19; Doença; Automedicação; Assistência farmacêutica.

\begin{abstract}
Objective: To verify the prevalence, risks, and factors that lead to self-medication, through an integrative literature review, searching for scientific studies in the central academic databases: Academic Google, Scielo, Medline, PubMed, and Redib. Methods: The literature review was conducted in October 2021, using the descriptors "Selfmedication", "Pandemia", "COVID-19", "risks", and "prevalence". Results: After using the inclusion and exclusion criteria, twelve articles were obtained for this analysis. They showed that the population did seek self-medication as a means of a quick and easy solution to the disease, as it is lethal and has considerable morbidity. Another justification for the use of self-medication was the mistaken preventive purpose, given the lack of scientific evidence on the treatment and/or prevention of COVID-19. Conclusion: Based on the results presented, it is highlighted that it is of great importance to carry out more studies that assess the indiscriminate use of drugs used in the treatment and/or prevention of the disease, and the importance of the pharmacist professional and the multidisciplinary team in providing guidance is also highlighted and promoting the rational use of medicines during the COVID-19 pandemic.
\end{abstract} Keywords: COVID-19; Illness; Self-medication; Pharmaceutical care.

\section{Resumen}

Objetivo: Verificar la prevalencia, riesgos y factores que conducen a la automedicación, mediante una revisión integradora de la literatura, buscando estudios científicos en las principales bases de datos académicas: Google Académico, Scielo, Medline, PubMed y Redib. Métodos: La revisión de la literatura se realizó en octubre de 2021, utilizando los descriptores "Automedicación", "Pandemia", "COVID-19", "riesgos" y "prevalencia". Resultados: Después de utilizar los criterios de inclusión y exclusión, se obtuvieron 12 artículos para este análisis. Demostraron que la población buscaba la automedicación como medio de solución rápida y fácil de la enfermedad, ya que es letal y tiene una morbilidad considerable. Otra justificación para el uso de la automedicación fue el propósito preventivo 
equivocado, dada la falta de evidencia científica sobre el tratamiento y / o prevención del COVID-19. Conclusión: A partir de los resultados presentados, se destaca que es de gran importancia realizar más estudios que evalúen el uso indiscriminado de fármacos utilizados en el tratamiento y / o prevención de la enfermedad, y la importancia del profesional farmacéutico y del equipo multidisciplinario. También se destaca en brindar orientación y promover el uso racional de medicamentos durante la pandemia de COVID-19.

Palabras clave: COVID-19; Enfermedad; Automedicación; Cuidado farmacéutico.

\section{Introdução}

Em dezembro de 2019, foi evidenciado na província de Wuhan, China, o primeiro caso de uma síndrome respiratória de espectro viral, inicialmente desconhecida, com característica infectocontagiosa, causada pelo vírus identificado como Severe Acute Respiratory Syndrome Coronavírus 2 (Sars-CoV-2), comumente conhecido como Coronavírus. Em março de 2020, já havia vários casos espalhados pelo mundo. Foi neste período, então, que a Organização Mundial da Saúde (OMS) declarou a pandemia mundial (OMS, 2021). As entidades de saúde nacionais e internacionais passaram a recomendar medidas preventivas para a eventual disseminação do vírus SARS-CoV-2, inicialmente com base na contingência utilizada na influenza (Freitas et al., 2020), que consiste na análise de indicadores de gravidade como a letalidade, mortalidade e complicações não comuns.

De acordo com a nota técnica $n^{\circ}$ 07/2020, publicada conjuntamente pela Gerência de Vigilância e Monitoramento em Serviços de Saúde, Gerência-Geral de Tecnologia em Serviços de Saúde e Agência Nacional de Vigilância Sanitária (GVIMS/GGTES/ANVISA, 2021), há três tipos de transmissões: transmissão pré-sintomática, transmissão sintomática e a transmissão assintomática. A transmissão pré-sintomática é aquele na qual o indivíduo infectado pode transmitir o vírus a partir de 48 horas antes dos primeiros sintomas; já a transmissão sintomática é aquela na qual há o contato com indivíduo infectado e sintomático; e, a transmissão assintomática é quando há confirmação laboratorial da doença, porém não desenvolve sintomas e mesmo assim o sujeito ainda é capaz transmitir.

A doença de alta letalidade e transmissibilidade, afeta o sistema respiratório, sendo que a febre, o cansaço e a tosse seca estão entre os principais sintomas, podendo apresentar também dores, congestão nasal, dor de cabeça, conjuntivite, dor de garganta, diarreia, perda de paladar ou olfato, erupção cutânea na pele ou descoloração dos dedos das mãos ou dos pés (Zhu et al., 2020). Os sintomas inicialmente são leves e podem gradualmente aumentar, de forma que, segundo a OMS (2021) uma em cada seis pessoas infectadas por COVID-19 fica gravemente doente e desenvolve dificuldade de respirar. A forma de contágio da doença, ocorre, sobretudo, através de gotículas saliva, espirro, tosse, catarro, contato pessoal próximo, toque ou aperto de mão, contato com objetos ou superfícies contaminadas, seguido de contato com a boca, nariz ou olhos (Ministério da Saúde, 2021).

A OMS (2020) aponta que os pacientes idosos, imunossuprimidos, vulneráveis e com comorbidades (hipertensos, doenças cardíacas, doenças pulmonares, diabetes, obesidade, câncer etc.), têm um risco aumentado de necessitar de internação e suporte ventilatório em ambiente de unidades de terapia intensiva (UTI). Nos estudos realizados por Yanez et al., (2020), dados de 16 países foram analisados e os resultados apresentados constam com altas taxas de mortalidade em indivíduos com mais 65 anos e os homens tinham um risco maior de morte por COVID-19 do que as mulheres.

Segundo o Conselho Regional de Farmácia (CRF-SP, 2020), nos três primeiros meses de 2020 houve um aumento de quase $200 \%$ no consumo de vitaminas e medicamentos. De acordo com definições estabelecidas pela OMS (1998), a automedicação é conceituada como a seleção e uso de medicamentos para tratar sintomas e doenças autorreferidas sem o aconselhamento do profissional de saúde qualificado para determinada função, compreendendo etapa do autocuidado. Essa prática é comum na sociedade e representa um problema grave de saúde pública. Prática essa realizada por $77 \%$ dos brasileiros (Conselho Federal de Farmácia, 2019).

De acordo com Gimenes et al. (2019), de forma mais abrangente, os fatores que influenciam a prática da automedicação são: a falta de acesso a serviços de saúde e a propaganda feita sobre os medicamentos livres de prescrição. Já 
durante a pandemia da COVID-19 o que levou (e leva) a sociedade a cometer essa prática é a prevenção do vírus, uma busca pela melhora dos sintomas ou até mesmo a cura.

De acordo com os dados da OMS, em torno da metade dos medicamentos são prescritos, dispensados e vendidos incorretamente, acarretando diversos fatores maléficos no tratamento do paciente, com o uso incorreto de medicamentos, que é um dos maiores problemas de Saúde Pública em todo mundo.

Nota-se também que nas farmácias houve uma grande busca por medicações no sentido de prevenção ou tratamento da COVID-19, por meio da prática da automedicação e da auto prescrição, na maioria das vezes influenciada por fake News (notícias falsas) disponibilizadas em mídias de TV, sites e redes sociais (Molento, 2020; Sharma et al., 2020). Todavia sabe-se que não há comprovação cientifica alguma, na prevenção e/ou tratamento da COVID-19 (Souza \& Tritany, 2020).

Em razão disso, pesquisas voltadas para a automedicação apresentam, além de um problema de saúde generalizado, os riscos causados por essa prática, que aumentou expressivamente os casos de intoxicação desde o início da pandemia da COVID-19. Em função dos questionamentos em torno da temática automedicação e terapia precoce, esta pesquisa teve por objetivo apresentar uma revisão integrativa da vasta literatura produzida sobre o que já foi discutido a respeito da prevalência, riscos e fatores que levam a realização da automedicação dentro do contexto da pandemia. Este estudo consistiu como uma base preliminar para o desenvolvimento de projeto de identificação da prevalência da automedicação em uma determinada população adulta.

\section{Metodologia}

O presente trabalho refere-se a um estudo de revisão integrativa de literatura com base em trabalhos que envolvem publicações científicas em relação a prática de automedicação durante o período de pandemia da COVID-19. A revisão abrangente é um método de revisão mais amplo porque permite pesquisas que incluem literatura teórica e empírica e usa diferentes metodologias. (Souza et al., 2010). Botelho et al. (2010) reforça que este tipo de método permite aproximar-se da problemática, possibilitando desenhar um panorama sobre a sua produção científica, dessa forma, o investigador passa a conhecer a evolução do tema ao longo do tempo e visualizar possíveis oportunidades de pesquisa. A escolha deste método ajudou na construção e evolução do projeto realizado pelos autores, no que tange a investigação a campo.

Delimitou-se os estudos que estivessem voltados para: prevalência, riscos e fatores que levam a automedicação no período de pandemia do Coronavírus.

Para a realização da revisão integrativa, utilizou-se o método proposto em Crossetti (2012), no qual é necessário partir da definição de seis etapas. Estas etapas são apresentadas de forma sintetizada e esquemática na Figura 1.

Figura 1 - Fluxo aplicado à pesquisa bibliográfica do tipo revisão integrativa.

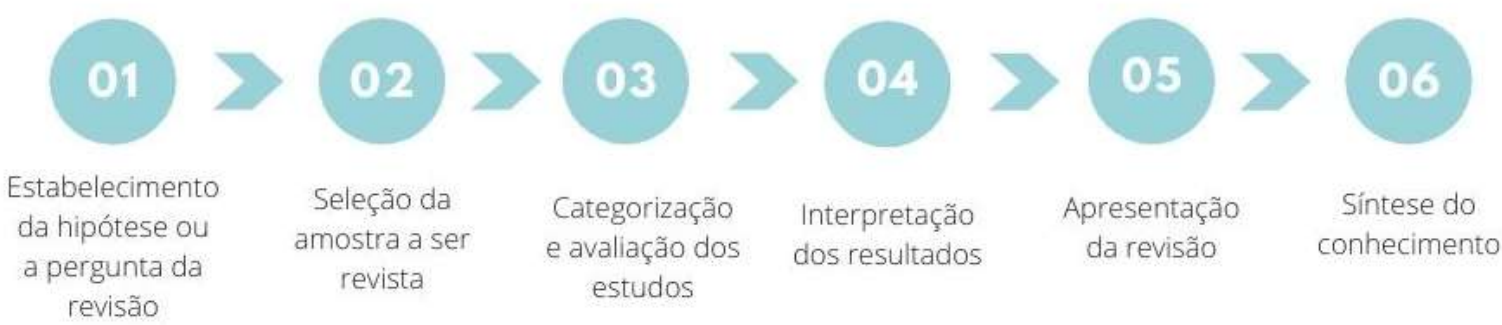

Fonte: Gomes et al. (2021) adaptado de Crossetti (2012).

O estudo foi realizado através de coletas de dados no qual houve busca de artigos científicos nas seguintes bases de 
dados: Google Acadêmico, Scientific Eletronic Library Online (Scielo), Online Medical Literature Analyses and Retrieval System Online (Medline), Medical Publications (PubMed) e Red Iberoamericana de Innovación y Conocimiento Científico (Redib). Foram utilizados como principais descritores os termos: "Automedicação", "Pandemia", "COVID-19", "riscos" e "prevalência". O fluxograma aplicado à seleção dos artigos está representado na Figura 2.

Figura 2 - Fluxograma do processo de seleção de artigos

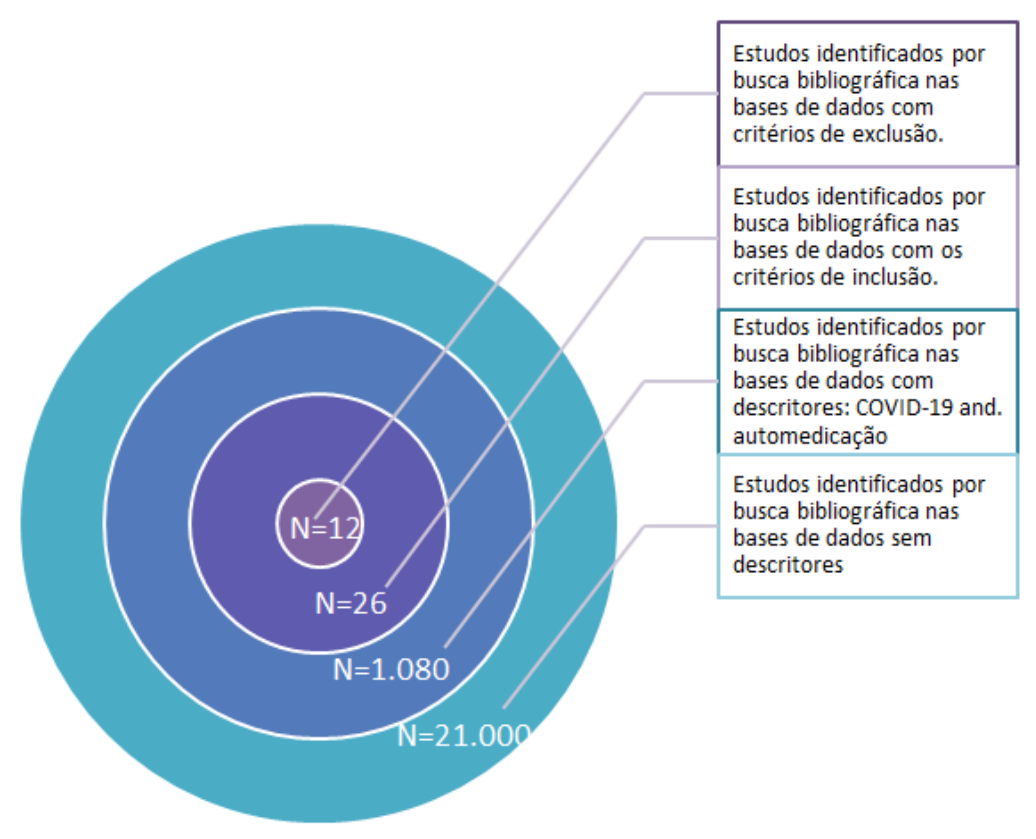

Fonte: Gomes et al. (2021)

As buscas foram realizadas no mês de outubro de 2021 e considerou-se por critérios de inclusão: artigos publicados em português e inglês; artigos científicos contendo os descritores; permissão de acesso integral ao conteúdo de estudo e estudos publicados a partir de 2020. Os critérios de exclusão foram: os que não atendiam a temática proposta; repetidos; que não obedeceram aos critérios de inclusão supracitados.

Os dados levantados passaram pela análise crítico-reflexiva, interpretação e foram apresentados na forma de síntese dos conhecimentos significativos produzidos no último ano dentro do contexto pandêmico que perdura.

\section{Resultados e Discussão}

Na primeira busca, considerando somente os critérios de inclusão, foram obtidos 26 artigos publicados nos anos de 2020 e 2021. Com esta base, foram aplicados os critérios de exclusão e, então, o resultado conduziu para a análise de 12 publicações, o que correspondeu a 42,3\% dos artigos levantados para a realização deste estudo (Tabela 1). A média de tempo entre a submissão e a publicação dos artigos em periódicos foi de 30 dias. Ressalta-se que houve grande necessidade de compreensão de diversos setores dentro do cenário da pandemia. Por isso, observou-se que grande parte das publicações em periódicos, com os indexadores escolhidos, foram divulgadas mais rapidamente do que quando se observa em contextos convencionais. 
Tabela 1 - Artigos analisados e as respectivas metodologias aplicadas à pesquisa.

\begin{tabular}{|c|c|c|c|}
\hline $\begin{array}{l}\text { Autores e Ano de } \\
\text { Publicação }\end{array}$ & Título & Periódico/Livro & Metodologia \\
\hline Cardoso, et al., 2020. & $\begin{array}{l}\text { Automedicação em tempos de Pandemia } \\
\text { Mundial }\end{array}$ & Biológicas e Saúde & Revisão bibliográfica. \\
\hline Gomes, et al., 2020. & $\begin{array}{l}\text { Riscos da Automedicação na Pandemia } \\
\text { por Covid-19: O dilema entre } \\
\text { informações midiáticas e Científicas }\end{array}$ & $\begin{array}{l}\text { Ciências da saúde no } \\
\text { Brasil: contribuições } \\
\text { para enfrentar os } \\
\text { desafios atuais } \quad \text { e } \\
\text { futuros. }\end{array}$ & Revisão bibliográfica. \\
\hline $\begin{array}{l}\text { Oliveira \& Mormino, } \\
2020 .\end{array}$ & $\begin{array}{l}\text { Os riscos da automedicação no } \\
\text { tratamento do COVID-19: Uma revisão } \\
\text { de literatura }\end{array}$ & $\begin{array}{l}\text { Encontro de Extensão, } \\
\text { Docência e Iniciação } \\
\text { Científica (EEDIC) }\end{array}$ & Revisão bibliográfica. \\
\hline $\begin{array}{l}\text { Carvalho \& Guimarães, } \\
2020 .\end{array}$ & $\begin{array}{l}\text { Desinformação, Negacionismo e } \\
\text { Automedicação: a relação da população } \\
\text { com as drogas "milagrosas" em meio à } \\
\text { pandemia da COVID-19 }\end{array}$ & $\begin{array}{l}\text { InterAmerican Journal } \\
\text { of Medicine and Health }\end{array}$ & Revisão bibliográfica. \\
\hline $\begin{array}{l}\text { Rocha Pitta, et al., } \\
\text { 2021. }\end{array}$ & $\begin{array}{l}\text { Análise do perfil de automedicação em } \\
\text { tempos de COVID-19 no Brasil }\end{array}$ & $\begin{array}{l}\text { Research, Society and } \\
\text { Development }\end{array}$ & $\begin{array}{l}\text { Entrevista com aplicação de questionário } \\
\text { virtual para coleta de dados. }\end{array}$ \\
\hline Ruiz, et al., 2021 & $\begin{array}{l}\text { A influência midiática para } \\
\text { automedicação do novo coronavírus: } \\
\text { revisão literária }\end{array}$ & $\begin{array}{l}\text { Research, Society and } \\
\text { Development. }\end{array}$ & Revisão bibliográfica. \\
\hline
\end{tabular}

\begin{tabular}{|c|c|c|c|}
\hline $\begin{array}{l}\text { Ferreira \& Carvalho, } \\
\text { 2021. }\end{array}$ & $\begin{array}{l}\text { A influência da propaganda } \text { de } \\
\text { medicamentos na prática da } \\
\text { automedicação: um problema de saúde } \\
\text { pública. }\end{array}$ & $\begin{array}{l}\text { Brazilian Journal of } \\
\text { Development }\end{array}$ & Revisão bibliográfica. \\
\hline Silva, et al., 2021. & $\begin{array}{l}\text { Automedicação na Pandemia do novo } \\
\text { Coronavírus. }\end{array}$ & $\begin{array}{l}\text { Revista Ibero- } \\
\text { Americana de } \\
\text { Humanidades, Ciências } \\
\text { e Educação }\end{array}$ & Revisão bibliográfica. \\
\hline Souza Leal et al., 2021. & $\begin{array}{l}\text { Análise da Automedicação durante a } \\
\text { Pandemia do novo Coronavírus: Um } \\
\text { olhar sobre a Azitromicina }\end{array}$ & $\begin{array}{l}\text { Revista Ibero- } \\
\text { Americana de } \\
\text { Humanidades, Ciências } \\
\text { e Educação }\end{array}$ & Revisão bibliográfica. \\
\hline $\begin{array}{l}\text { Tritany \& Tritany, } \\
2020 .\end{array}$ & $\begin{array}{l}\text { Uso Racional de Medicamentos para } \\
\text { COVID-19 na Atenção Primária à Saúde }\end{array}$ & Saúde em Redes & Revisão bibliográfica. \\
\hline Andrade et al., 2021. & $\begin{array}{l}\text { Perfil de uso de medicamentos e } \\
\text { automedicação, em uma população } \\
\text { universitária, frente a pandemia da } \\
\text { Covid-19. }\end{array}$ & $\begin{array}{l}\text { Brazilian Journal of } \\
\text { Development }\end{array}$ & $\begin{array}{l}\text { Estudo observacional, através de um } \\
\text { questionário virtual para coleta de dados. }\end{array}$ \\
\hline $\begin{array}{lll}\text { Silva Júnior } \quad \& \\
\text { Gonzalez, } & 2021\end{array}$ & $\begin{array}{l}\text { Automedicação e Efeitos Psicológicos em } \\
\text { Idosos Durante o Isolamento Social }\end{array}$ & Atena Editora & Revisão bibliográfica. \\
\hline
\end{tabular}

Fonte: Gomes et al. (2021).

Observou-se que apenas 2 de 12 artigos analisados, partiram de estudos com base em dados primários, obtidos a partir de entrevistas no ambiente virtual. Sendo que as outras 10 publicações abordaram suas temáticas por meio de revisão da 
literatura. De forma geral, as publicações apresentam a discussão sobre a conscientização e alerta para a população sobre os perigos do consumo de medicamentos sem prescrição ou orientação de um profissional da área da saúde habilitado; bem como há enfoque ao problema de saúde pública gerado pela disseminação de notícias e informações falsas. O hábito da automedicação não acontece apenas no Brasil, é um problema de saúde que ocorre a nível mundial, visto que o Brasil é considerado o maior consumidor de medicamentos da América Latina (Delgado \& Vriesmann, 2018).

Dentre os estudos analisados, que partiram da coleta de dados primários, Rocha Pitta et al. (2021) apresentaram maior amostragem. Estes autores coletaram dados no segundo semestre de 2020, por meio de 1.000 (um mil) questionários que foram aplicados on-line, devido às restrições impostas para realização de entrevistas presenciais no contexto da pandemia. Seus resultados evidenciaram que a classe de vitaminas e a Ivermectina foram os medicamentos de maior prevalência entre os entrevistados.

A Ivermectina esteve no foco do tratamento para COVID-19 em várias cidades do Brasil, porém Maciel et al. (2021) mostraram que ainda há controvérsia na comunidade científica em relação à efetiva eficácia do medicamento para o tratamento da doença do coronavírus. De acordo com a revisão integrativa realizada pelos autores, há algumas limitações metodológicas na maioria dos estudos e se evidencia a necessidade de estudos clínicos bem desenhados e estruturados que realmente possam confirmar ou descartar o uso do medicamento para este fim. No entanto, mesmo com as incertezas quanto ao uso da Ivermectina, o medicamento continua sendo aplicado e utilizado nos protocolos de tratamento para COVID-19 no país e, o mais preocupante, tem sido seu uso indiscriminado, sem nenhuma prescrição médica.

No Brasil, a prática da automedicação ocorre com maior frequência em pessoas do sexo feminino e que, geralmente estão se automedicando baseados em prescrições médicas antigas e/ou por pessoas leigas. A automedicação apresenta diversos riscos, pois a prática da mesma, pode estar mascarando sintomas e dificultar o diagnóstico de uma doença mais grave, além dos possíveis efeitos indesejáveis que ela pode trazer (Cardoso et al., 2020).

Segundo Rocha Pitta (2021), indivíduos do sexo feminino tem a maior prevalência da automedicação para prevenção da COVID-19, pertencentes a faixa etária a partir de 40 anos, de etnia indígena e preta, com nível de escolaridade de nível médio, de renda familiar média de 4-5 salários-mínimos, seguido daqueles que recebem mais de 10 salários-mínimos e são moradores da região Norte.

Isolamento e distanciamento social foram adotados como medidas preventivas à propagação do vírus e controle da pandemia, com isso houve um grande aumento na comunicação on-line, tendo as mídias sociais como importante via de comunicação para o repasse das informações, o que trouxe diversos impactos tantos positivos como negativos. Como impactos positivos cita-se: a divulgação medidas de higiene sanitária (lavagens das mãos, higienização de superfícies); segurança ("fique em casa"); medidas de isolamento e distanciamento social. Como impactos negativos, podem ser citados: a divulgação sobre medicamentos ainda em estudo, porém ainda sem a eficácia comprovada, para combate ao Coronavírus. Os claros exemplos são os medicamentos: cloroquina, hidroxicloroquina e ivermectina. Neste cenário, a população acaba gerando uma enorme demanda nas farmácias para a obtenção dos medicamentos, e causando assim uma grande carência das medicações paras pessoas que já faziam uso das medicações para outras patologias, como no caso da cloroquina utilizada para o Lúpus. (Godfrey, 2020).

A internet tem sido importante via de acesso às notícias durante a pandemia, porém, tornou- se uma grande contribuidora para o compartilhamento de Fake News, podendo causar grandes problemas à população, principalmente aqueles que detém de pouco acesso a conhecimentos científicos (Carvalho \& Guimarães, 2020). As divulgações ocorridas por meio de recursos midiáticos acabam tendo grande poder de influência sobre as pessoas em relação a automedicação, principalmente quando se fala de medicamentos isentos da prescrição de um profissional habilitado, como um médico ou um farmacêutico. Além disso, a indústria farmacêutica acaba sendo uma propulsora das propagandas e do marketing sobre medicamentos, o que 
já era esperado visto que este setor acaba sendo um dos mais rentáveis do mundo em relação a lucros. Por outro lado, pode ocorrer certa negligência no que tange às informações adequadas que chegam à sociedade e ao consumidor (Ruiz et al., 2021). $\mathrm{O}$ advento dos meios midiáticos, principalmente através das mídias sociais com sua rapidez de disseminação da informação, acaba por ser um dos grandes fomentadores para o alto consumo de medicamentos (Gomes et al., 2020).

Ferreira \& Carvalho (2021), descreveram os fatores adversos que contribuem para que as pessoas se automediquem, mencionando a jornada de trabalho intensa e a rotina familiar e estudantil, que é o que toma maior parte do tempo de um indivíduo, utilizando a automedicação como o alívio rápido de certas enfermidades, para que não desperdicem seu tempo e influa na atividade cotidiana. A desinformação e o temor são fatores de motivação que influenciam a pratica do uso de fármacos sem a devida prescrição (Oliveira \& Mormino, 2020). A OMS (2020) relata que outro fator que influenciou essa prática durante o período de pandemia foi a ausência de medicamentos que atuem na atenuação, ou que possam ajudar diretamente no tratamento da COVID-19, o que consequentemente levou a elevados números de transtornos psicológicos, como por exemplo, estresse, distúrbios da ansiedade e depressão, despertados a partir das notícias e do alto índices de óbitos ocasionados em todo o mundo.

De acordo com Carvalho \& Guimarães (2020), um dos motivos que também levou a prática da automedicação durante a pandemia foi o descrédito depositado na ciência, fazendo com o que a população se submetesse a perigos com a própria saúde, já que o consumo de medicamentos faz com que a população crie uma espécie de falsa sensação de proteção contra a COVID-19. Este comportamento, associado à descrença científica, podem culminar no desrespeito ao isolamento social, às regras de distanciamento, protocolos de biossegurança e, consequentemente, no crescimento da curva de infectados e hospitalizados.

$\mathrm{O}$ ato de se automedicar, atrela a si diversos perigos, um deles diz respeito aos efeitos colaterais ocasionados pela interação medicamento/medicamento ou medicamento/alimento, o que aumenta o número de comorbidades e mortalidades em tempos de pandemia, uma vez que, o sistema de saúde se encontra engajado no combate da COVID-19 (Makowska et al., 2020). Segundo Souza (2021), os antibióticos diminuem as taxas de morbimortalidade por infecção bacteriana em escala global. Mas, com o passar do tempo, o consumo exacerbado, inadequado e sem prescrição, o aumento de casos de resistência bacteriana aos antimicrobianos serão elevados, fazendo-se necessárias elaborações de medidas preventivas, visando a melhoria e minimização dos efeitos da resistência bacteriana, bem como evitar novas cepas multirresistentes.

Segundo Souza et al. (2021), 30,1\% dos participantes de uma pesquisa, afirmam realizar a automedicação com o intuito de prevenir ou tratar a infecção causada pelo SARS-CoV-2, dentre eles $14,2 \%$ fizeram a automedicação da azitromicina. Devido não haver fármacos que atuem na profilaxia, ou que trabalhem de forma direta no tratamento, observouse que a população intensificou o seu comportamento em automedicar-se, acreditando estar mais segura, como uma forma de prevenir a doença. Outro fator que se observou foi um enorme aumento da procura por suplementos alimentares, como vitaminas e minerais, no intuito de fortalecer o sistema imunológico e estar se prevenindo da infecção pelo vírus (Tritany \& Tritany, 2020; OMS, 2020). Acúmulo indevido do fármaco no organismo, potenciais interações medicamentosas, erro na dosagem, inadequação do tempo de tratamento, ocorrência de efeitos adversos graves e o autodiagnóstico incorreto, estão entre os principais riscos atrelados a prática da automedicação (Gomes, 2020).

Andrade et al. (2021), realizou uma pesquisa com uma amostra de 59 universitários e buscou avaliar o perfil de uso de medicamentos e automedicação, frente a pandemia da COVID-19, onde $84,75 \%$ da amostra afirmaram que realizam a automedicação, e muitos informaram acreditar nos medicamentos sem eficácia comprovada, inclusive fazendo uso de medicamentos divulgados pela mídia e por pessoas influentes, como as do meio político.

Silva, (2021), em sua revisão de literatura, listou os medicamentos mais citados em artigos científicos no período de julho de 2020 a fevereiro de 2021, onde o autor usou um gráfico com as variantes Volume quote (VQ) relacionado ao volume 
de citação do medicamento em artigos científicos, além do Medician quote (MQ) que indica quais medicamentos foram citados. Os resultados desta pesquisa foram os medicamentos Cloroquina e Hidroxicloroquina, vitamina C, Ivermectina, Azitromicina, Ibuprofeno, Lopinavir e Ritonavir. Ele relatou também que o Vitamina $\mathrm{C}$ e as Multivitaminas, são muito perigosas, pois têm o potencial de Hipervitaminose, e pode causar efeitos adversos como qualquer outro medicamento, tais como: náusea, vômito, dores de estômago e dor de cabeça.

Dentre os profissionais que atuaram e continuam atuando em equipes multidisciplinares dos hospitais e centros de saúde que atuam no combate à COVID-19, destaca-se a notória importância do farmacêutico. Fuzari et al. (2021) ressaltaram o fato de que em contextos pandêmicos, os recursos ficam escassos e a presença do farmacêutico é crucial na elaboração de protocolos para uso seguro e racional de medicamentos, padronização de medicamentos, avaliação de estabilidade e, se possível, coordenação de uma farmácia satélite. No que se refere à automedicação, principalmente em meio à pandemia, Da Silva Júnior \& Gonzales, (2021) destacam a importância desse profissional no controle e orientação de métodos ideias do tratamento da COVID-19, fazendo com que haja redução dos altos indicies de automedicação e das consequências advindas desta prática.

\section{Conclusão}

Infere-se que mesmo em um período de aproximadamente dois anos de pandemia, os dados expressam a importância da temática automedicação dentro do cenário de crise sanitária. Ratifica-se, por meio de dados de publicações, que a população faz um consumo demasiado de medicamentos sem a prescrição de um profissional habilitado, ficando sujeita aos grandes riscos que eles podem causar, desde sintomas leves até uma intoxicação, visto que não há evidências cientificas ainda sobre medicações na prevenção, profilaxia e tratamento da COVID-19.

Os altos índices de mortes foram uma das principais causas (e talvez consequências) da automedicação. A insegurança e o medo levaram as pessoas às tentativas de "prevenir" a doença. Ressalta-se a notoriedade e importância da equipe multidisciplinar, essencialmente o profissional farmacêutico na orientação e no uso racional de medicamentos.

Recomenda-se que os profissionais se mantenham sempre atualizados em relação ao vírus, que sempre façam uma triagem das informações antes de repassar aos indivíduos, e que a população sempre busque informações atualizadas e de fontes confiáveis.

Por fim, sugere-se que o uso das mídias sociais seja para que haja a disseminação de informações fundamentadas com embasamento científico, de forma clara a população, alertando sempre os riscos que podem estar sujeitos ao praticarem a automedicação ser pertinente aos dados apresentados. Além disso, recomenda-se também que sejam desenvolvidos estudos futuros sobre a automedicação e seus riscos voltados para grupos especiais: idosos, crianças, pessoas em situações de obesidade, cardiopatas, hipertensos, diabéticos e pessoas com algum tipo de câncer.

\section{Agradecimentos}

Os autores expressam seus agradecimentos ao Centro Universitário da Amazônia (UNAMA Santarém), em especial aos professores do curso de Bacharelado em Farmácia por toda a formação ofertada pela instituição.

\section{Referências}

Andrade E. A., et al. (2021). Perfil de uso de medicamentos e automedicação, em uma população universitária, frente a pandemia da Covid-19. Brazilian Journal of Development, v. 7, n. 7, p. 73772-73784.

Botelho L. L. R., et al. (2011). O método da revisão integrativa nos estudos organizacionais. Gestão e sociedade, v. 5, n. 11, p. $121-136$. 
Cardoso C. S. J., et al. (2020). Automedicação em tempos de Pandemia Mundial. In: BIOLÓGICAS E SAÚDE. http://www.metodista.br/congressoscientificos/index.php/Congresso2020/SDE2020/paper/view/10927.

Carvalho W. \& Guimarães A. S. (2020). Desinformação, Negacionismo e Automedicação: a relação da população com as drogas "milagrosas" em meio à pandemia da COVID-19. InterAmerican Journal of Medicine and Health, v. 3.

CCP, NCHS. (2021). Centros de Controle e Prevenção de Doenças. Centro Nacional para Estatísticas de saúde (NCHS). Atualizações semanais por grupos demográficos selecionados e características geográficas. Contagem provisória de mortes por coronavírus Doença 2019 (COVID-19). CDC; https://www.cdc.gov/nchs/nvss/vsrr/covid_weekly/index.htm.

CFF - Conselho Federal de Farmácia. (2019). Quase metade dos brasileiros que usaram medicamentos nos últimos seis meses se automedicou até uma vez por mês. https://www.cff.org.br/noticia.php?id=5267.

CRF-SP. (2020). Aleta sobre o aumento da automedicação durante a pandemia. Informativos Técnicos - CRF-SP [blog] Conselho Regional de Farmácia do Estado de São Paulo. http://www.crfsp.org.br/noticias-da-regiao/sao-jose-do-rio-preto/11272-alerta-do-crf-sp-sobre-aumento-daautomedica\%C3\%A7\%C3\%A3o-durante-a-pandemia-\%C3\%A9-destaque-na-tv-rio-preto.html.

Crossetti M. G. O. (2012). Revisão integrativa de pesquisa na enfermagem o rigor científico que lhe é exigido. Revista gaúcha de enfermagem, v. 33, n. 2, p. $8-9,2012$.

Da Rocha Pitta M. G., et al. (2021) Análise do perfil de automedicação em tempos de COVID-19 no Brasil. Research, Society and Development, v. 10, n. 11, p. e28101119296-e28101119296.

Da Silva Júnior E.L. \& Gonzalez L. F. C. (2021) Automedicação e Efeitos Psicológicos em Idosos Durante o Isolamento Social. Automedicação e Efeitos Psicológicos em Idosos Durante o Isolamento Social, Editora Atena, p. 1-388-416.

De Souza Leal W. et al. (2021). Análise da Automedicação durante a Pandemia do novo Coronavírus: Um olhar sobre a Azitromicina. Revista IberoAmericana de Humanidades, Ciências e Educação, v. 7, n. 8, p. 580-592.

Delgado A. F. S. \& Vriesmann L. C. (2018). O perfil da automedicação na sociedade brasileira. Revista Saúde e Desenvolvimento, v. 12, n. 11, p. 57-75.

Ferreira I. S. \& De Carvalho C. J. S. (2021). A influência da propaganda de medicamentos na prática da automedicação: um problema de saúde pública. Brazilian Journal of Development, v. 7, n. 5, p. 47642-47652.

Freitas A. R. R. \& Napimoga M. \& Donalisio M. R. (2020). Análise da gravidade da pandemia de Covid-19. Epidemiologia e Serviços de Saúde, v. 29, p. e2020119.

Fuzari W. M. P. et al. (2021) Atuação do farmacêutico clínico frente à COVID-19 em um hospital público da região amazônica. Revista Eletrônica Acervo Saúde, v. 13, n. 5, p. e6450-e6450.

Godfrey L. (2020). Social Media's Role in the Coronavirus Pandemic. https://www.business2community.com/social-media/social-medias-role-in-thecoronavirus-pandemic-02296280.

Gomes A. H. D. et al. (2020). Riscos da Automedicação na Pandemia por Covid-19: O dilema entre informações midiáticas e Científicas. Ciências da saúde no Brasil: contribuições para enfrentar os desafios atuais e futuros. Copyright $\odot$ Editora Amplla Editor Chefe: Leonardo Pereira Tavares, p. 40.

Makowska M. et al. (2020). Comportamentos relacionados à automedicação na Polônia: confinamento da COVID-19., Jornal Internacional de Pesquisa Ambiental e Saúde Pública., v.14, nº344, p.1-19.

Maciel N. et al. (2021). Uso da ivermectina no tratamento da COVID-19 em humanos: revisão integrativa. Research, Society and Development, v. 10, n. 12, p. e564101220835-e564101220835.

Malik M. et al. (2020). Automedicação durante a pandemia de Covid-19: desafios e oportunidades. Drugs Ther Perspect. 1-3. doi: 10.1007 / s40267-02000785-z. https://www.ncbi.nlm.nih.gov/pmc/articles/PMC7532737/.

Ministério Da Saúde. Novo Coronavírus (Covid-19). (2021). informações básicas. Biblioteca Virtual em Saúde. https://bvsms.saude.gov.br/novo-coronaviruscovid-19-informacoes-basicas/.

Molento M. B. (2020). COVID-19 and the rush for self-medication and self-dosing with ivermectin: A word of caution. One Health, v.10, p.1-2.

Mota D. M. \& Vigo A. \& Kuchenbecker R. S. (2019). Reações adversas a medicamentos no sistema de farmacovigilância do Brasil, 2008 a 2013: estudo descritivo. Cadernos de Saúde Pública, v. 35, p. e00148818.

Nota Técnica. GVIMS/GGTES/ANVISA Nº 07/2020. (2021). Orientações para prevenção e vigilância epidemiológica das infecções por SAR-COV-2 (Covid19) dentro dos serviços de saúde. https://www.gov.br/anvisa/pt-br/centraisdeconteudo/publicacoes/servicosdesaude/notas-tecnicas/nota-tecnica-gvims-ggtesanvisa-no-07-2020.

Oliveira J. V. L. et al. A automedicação no período de pandemia de COVID-19: Revisão integrativa. Research, Society and Development, v. 10, n. 3, p. e58610313762-e58610313762, 2021.

Oliveira A. G. L. \& Mormino K. B. N. T. (2020). Os riscos da automedicação no tratamento do COVID-19: Uma revisão de literatura. Encontro de Extensão, Docência e Iniciação Científica (EEDIC), v. 7.

OMS. (2002). Promover o uso racional de medicamentos: componentes essenciais. Promoção do uso racional de medicamentos: componentes centrais. https://apps.who.int/iris/handle/10665/67438. 
Research, Society and Development, v. 10, n. 16, e308101624049, 2021

(CC BY 4.0) | ISSN 2525-3409 | DOI: http://dx.doi.org/10.33448/rsd-v10i16.24049

$\begin{aligned} & \text { OMS. } \\ & \text { https://www.paho.org/bra/index.php?option=com_content\&view=article\&id=6101:covid19\&Itemid=875. }\end{aligned}$
$\begin{aligned} & \text { OMS. (1998). O p papel do farmacêutico no } \\ & \text { http://apps.who.int/medicinedocs/pdf/whozip32e/whozip32e.pdf. }\end{aligned}$

Ruiz J. M. G. et al. (2021). A influência midiática para automedicação do novo coronavírus: revisão literária. Research, Society and Development, v. 10, n. 13, p. e53101321015-e53101321015.

Sharma K. et al. (2020) COVID-19 na mídia social: analisando desinformações em conversas no twitter. Cornell University Library. 4(1), 1-13.

Souza Filho B. A. B. \& Tritany E. F. (2020) COVID-19: importância das novas tecnologias para a prática de atividades físicas como estratégia de saúde pública. Cadernos de Saúde Pública, v. 36, p. e00054420.

Souza M. N. C. et al. (2021). Ocorrência de Automedicação na população Brasileira como estratégia preventiva ao SARS-CoV-2. Research, Society and Development, v. 10, n. 1, p. e44510111933-e44510111933.

Souza M. T. et al. (2010). Rachel de. Revisão integrativa: o que é e como fazer. Einstein (São Paulo), v. 8, p. 102-106.

Tritany R.F. \& Tritany E. F. (2020). Uso Racional de Medicamentos para COVID-19 na Atenção Primária à Saúde. Saúde em Redes, v. 6, n. 2 Suplem.

Yanez N. D. et al. (2020) COVID-19 mortality risk for older men and women. BMC Public Health, v. 20, n. 1, p. 1-7.

Zhu N., et al. (2020). A novel coronavirus from patients with pneumonia in China, 2019. N Engl J Med. 382(8), 727-733. 